\title{
Transcriptomic changes in the frontal cortex associated with paternal age
}

\author{
Rebecca G Smith', Cathy Fernandes ${ }^{1}$, Rachel Kember ${ }^{1}$, Leonard C Schalkwyk1', Joseph Buxbaum², \\ Abraham Reichenberg ${ }^{1,2}$ and Jonathan Mill ${ }^{1,3^{*}}$
}

\begin{abstract}
Background: Advanced paternal age is robustly associated with several human neuropsychiatric disorders, particularly autism. The precise mechanism(s) mediating the paternal age effect are not known, but they are thought to involve the accumulation of de novo (epi)genomic alterations. In this study we investigate differences in the frontal cortex transcriptome in a mouse model of advanced paternal age.

Findings: Transcriptomic profiling was undertaken for medial prefrontal cortex tissue dissected from the male offspring of young fathers ( 2 month old, 4 sires, $n=16$ offspring) and old fathers (10 month old, 6 sires, $n=16$ offspring) in a mouse model of advancing paternal age. We found a number of differentially expressed genes in the offspring of older fathers, many previously implicated in the aetiology of autism. Pathway analysis highlighted significant enrichment for changes in functional networks involved in inflammation and inflammatory disease, which are also implicated in autism.

Conclusions: We observed widespread alterations to the transcriptome associated with advanced paternal age with an enrichment of genes associated with inflammation, an interesting observation given previous evidence linking the immune system to several neuropsychiatric disorders including autism.
\end{abstract}

Keywords: Autism, Advanced paternal age, Gene expression, Transcriptome, Inflammation, Immune response, Brain

\section{Findings}

\section{Background}

Advanced paternal age is robustly associated with several neuropsychiatric disorders, most notably autism [1]. The mechanism(s) underlying this paternal age effect are not known, although the accumulation of de novo (epi)genetic changes over time in the male germ line are thought to be important. Evidence to support this hypothesis comes from preliminary data showing a higher rate of $d e$ novo mutations [2] and altered DNA methylation at birth [3] with increasing paternal age in humans, and increased de novo copy number variation (CNV) [4] and altered brain DNA methylation at imprinted loci in rodent models of advanced paternal age [5].

Gene expression changes associated with aging in the brain have been investigated largely in terms of

\footnotetext{
* Correspondence: j.mill@exeter.ac.uk

'Institute of Psychiatry, King's College London, De Crespigny Park, Denmark Hill, London SE5 8AF, UK

${ }^{3}$ University of Exeter Medical School, St Luke's Campus, Magdalen Rd, Exeter EX1 2LU, UK

Full list of author information is available at the end of the article
}

neurodegeneration and dementia [6], although aging per $s e$ is associated with widespread transcriptional changes [7]. In a study of aging using mice, for example, brain samples from the cerebellum and neocortex had increased expression of genes related to inflammatory and stress responses and decreased expression of genes associated with growth and trophic factors, protein turnover, DNA synthesis and repair, and neurotransmission [8]. Age-associated changes have been observed in numerous tissue and cell types, including the germ line. Of relevance to paternal age, an expression study of rats of different ages identified over 2,800 loci that are differentially expressed in spermatocytes from older males (18 months) compared to spermatocytes from young males (4 months); of note, many genes associated with base excision repair, nucleotide excision repair, mismatch repair and double strand break repair were altered in spermatocytes from older males [9]. In an analysis of RNA from the spermatogonial stem cells of mice of four different ages (6 days, 21 days, 60 days and 8 months) using microarrays, 2,819 genes had differential expression between the age groups 
$(P<0.05$, fold change $>2)$ including genes previously identified in gene expression studies of aging in stem cells [10]. Pathway analysis of these genes highlighted an enrichment of genes involved in DNA repair and oxidative stress, which is interesting given the known increase in DNA damage in the spermatozoa of older males. To date, only one study has looked at gene expression changes associated with paternal age in humans [11]. In this study of paternal age and autism, a decrease in the overall variance of gene expression was observed in the offspring of older fathers, in addition to a downregulation of genes involved in gene transcription [11]. To date, no research has examined transcriptomic changes in the brain in the context of advanced paternal age.

\section{Methods}

C57BL/6J mice were bred and maintained in the Biological Services Unit at the Institute of Psychiatry, Kings
College London, using stocks purchased from Charles River Laboratories. All animal experiments received the approval of the local ethical review panel of King's College London and were performed in compliance with the UK's Animals (Scientific Procedures) Act 1986. The work was carried out under licence (PPL 70/7184) and all efforts were made to minimize animal suffering and to reduce the number of animals used. We used tissue collected from an experimentally controlled rodent model of advancing paternal age (described in detail previously [5]) to examine whether the offspring of older fathers have altered levels of gene expression. Male offspring of 'young' fathers (2 month old, $n=16$, four sires with one litter each) and 'old' fathers (10 month old, $n=16$, six sires with one litter each), with at least two individuals selected from each family, were used in this study (see Additional file 1 for an overview of the samples used). All dissections were performed by a
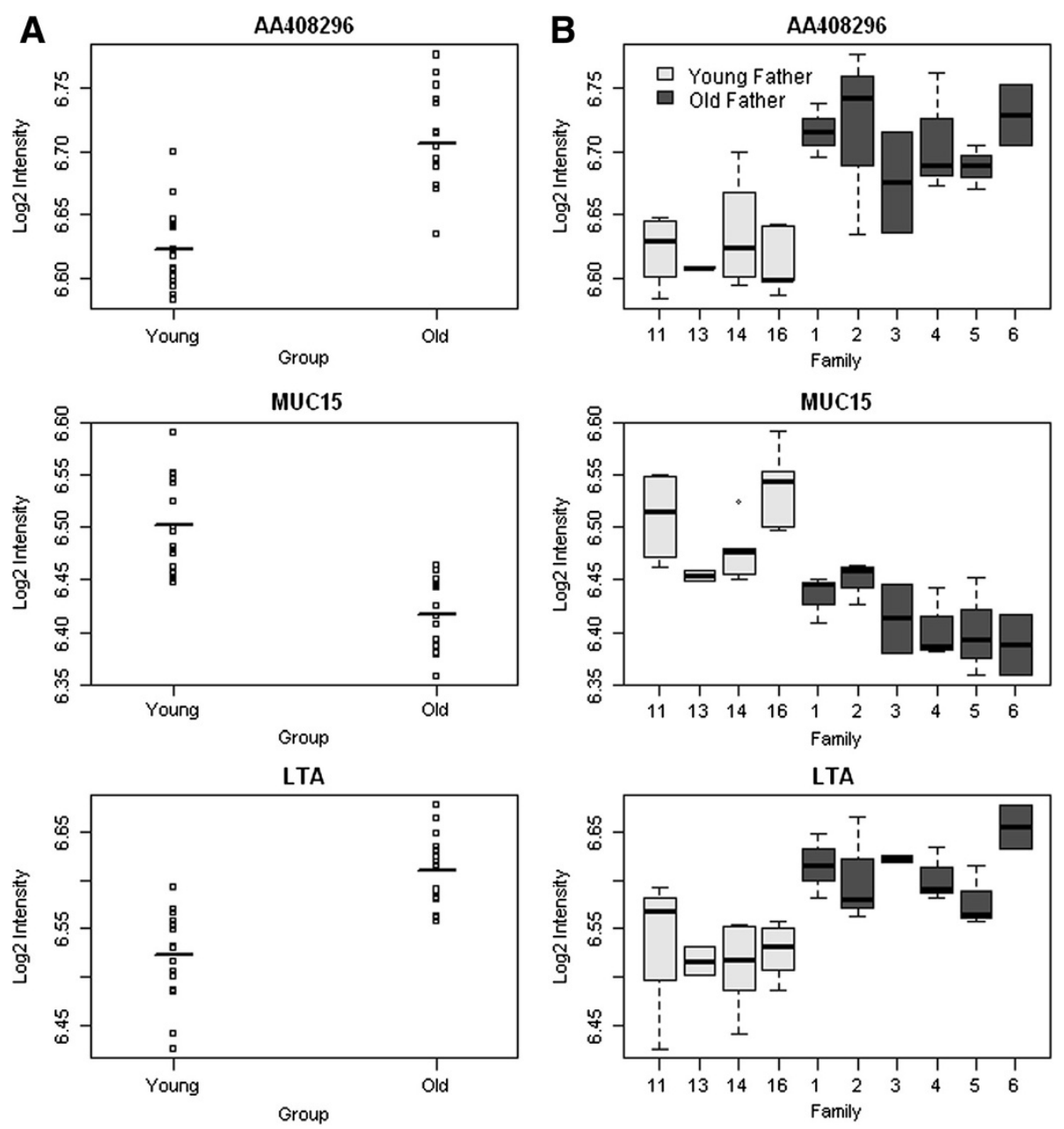

Figure 1 Top-ranked differentially expressed transcripts between the offspring of young fathers and offspring of old fathers. Shown for each probe (associated with the genes AA408296, Muc15 and Lta) are (A) group-level differences and (B) data split by family. The $y$-axis shows the $\log _{2}$ transformed signal intensity. 
single individual to ensure topographical similarity between samples. Briefly, brains were removed from the skull and placed dorsal side down on a wetted filter paper on a petri dish kept on ice. The cerebral halves were opened out from the midline, after cutting through the corpus callosum. Approximately $3 \mathrm{~mm}^{3}$ of tissue was cut from the anterior part of the frontal lobes (from bregma $2.46 \mathrm{~mm}$ to $1.34 \mathrm{~mm}$ [12]), mainly containing the medial prefrontal cortex including some prelimbic cortex, infralimbic cortex, cingulate cortex and motor cortex [13].
High quality RNA (average RNA integrity number (RIN) 8.4) was isolated using the Qiagen AllPrep DNA/ RNA Micro Kit (Qiagen, Manchester, UK). Gene expression was quantified using the Illumina Mouse Ref8 V2 array (Illumina, San Diego, CA, USA), which targets approximately 25,600 transcripts and over 19,100 unique genes. After stringent quality control and preprocessing, raw expression data were batch-corrected using the ComBat package [14] before being normalized and analysed using lumi [15] within the R statistical environment. All analysis scripts are available on request from the authors.

Table 1 Probes showing gene expression differences associated with paternal age $(P<0.001)$

\begin{tabular}{|c|c|c|c|c|c|}
\hline Transcript & Probe ID & Expression difference $^{a}$ & $P$ value & Mean (SEM) young & Mean (SEM) old \\
\hline AA408296 & 4150356 & $\uparrow$ & $3.23 \times 10^{-6}$ & $6.62(0.01)$ & $6.71(0.01)$ \\
\hline Muc15 & 2120176 & $\downarrow$ & $7.45 \times 10^{-6}$ & $6.5(0.01)$ & $6.42(0.01)$ \\
\hline Lta & 2900474 & $\uparrow$ & $7.46 \times 10^{-6}$ & $6.52(0.01)$ & $6.61(0.01)$ \\
\hline$T s / p$ & 6960520 & $\uparrow$ & $3.02 \times 10^{-5}$ & $6.41(0.01)$ & $6.48(0.01)$ \\
\hline Zfp35 & 580168 & $\downarrow$ & $1.30 \times 10^{-4}$ & $6.99(0.02)$ & $6.89(0.01)$ \\
\hline Gstm1 & 4540458 & $\uparrow$ & $1.31 \times 10^{-4}$ & $6.57(0.02)$ & $6.66(0.01)$ \\
\hline Rdh20 & 6840020 & $\uparrow$ & $1.38 \times 10^{-4}$ & $6.48(0.01)$ & $6.56(0.01)$ \\
\hline Ccdc90b & 6100215 & $\uparrow$ & $1.91 \times 10^{-4}$ & $7.1(0.02)$ & $7.22(0.02)$ \\
\hline sdhe & 3290630 & $\downarrow$ & $2.10 \times 10^{-4}$ & $6.48(0.01)$ & $6.4(0.02)$ \\
\hline Atp5sl & 5270131 & $\downarrow$ & $2.97 \times 10^{-4}$ & $7.76(0.02)$ & $7.61(0.03)$ \\
\hline Olfr187 & 380370 & $\downarrow$ & $3.07 \times 10^{-4}$ & $6.59(0.01)$ & $6.51(0.01)$ \\
\hline $\mathrm{Cd} 44$ & 4880138 & $\downarrow$ & $3.29 \times 10^{-4}$ & $6.64(0.01)$ & $6.57(0.01)$ \\
\hline Fryl & 510059 & $\uparrow$ & $3.58 \times 10^{-4}$ & $6.57(0.01)$ & $6.64(0.01)$ \\
\hline Accn 1 & 7330561 & $\uparrow$ & $3.59 \times 10^{-4}$ & $6.69(0.01)$ & $6.76(0.01)$ \\
\hline Cd177 & 670452 & $\downarrow$ & $3.71 \times 10^{-4}$ & $6.51(0.01)$ & $6.43(0.01)$ \\
\hline Tspan3 & 3130497 & $\uparrow$ & $3.96 \times 10^{-4}$ & $10.33(0.04)$ & $10.49(0.03)$ \\
\hline Olfr92 & 2710201 & $\uparrow$ & $4.29 \times 10^{-4}$ & $6.47(0.01)$ & $6.53(0.01)$ \\
\hline Shh & 2260450 & $\uparrow$ & $4.37 \times 10^{-4}$ & $6.71(0.02)$ & $6.79(0.01)$ \\
\hline E130303B06RIK & 6250669 & $\downarrow$ & $4.38 \times 10^{-4}$ & $6.67(0.01)$ & $6.59(0.01)$ \\
\hline Arhgap6 & 7550333 & $\downarrow$ & $4.43 \times 10^{-4}$ & $6.45(0.01)$ & $6.39(0.01)$ \\
\hline Zc3h18 & 7380382 & $\uparrow$ & $5.21 \times 10^{-4}$ & $7(0.01)$ & $7.08(0.02)$ \\
\hline $\operatorname{Atg} 5$ & 3850450 & $\downarrow$ & $6.10 \times 10^{-4}$ & $7.98(0.02)$ & $7.9(0.01)$ \\
\hline Nsflic & 7610433 & $\downarrow$ & $7.45 \times 10^{-4}$ & $7.69(0.02)$ & $7.55(0.03)$ \\
\hline Ear12 & 4540543 & $\downarrow$ & $7.47 \times 10^{-4}$ & $6.52(0.01)$ & $6.46(0.01)$ \\
\hline Olfr1366 & 6860093 & $\downarrow$ & $7.69 \times 10^{-4}$ & $6.49(0.02)$ & $6.41(0.01)$ \\
\hline Tnfsf11 & 2480255 & $\uparrow$ & $8.20 \times 10^{-4}$ & $6.5(0.01)$ & $6.57(0.01)$ \\
\hline Lcorl & 2470343 & $\downarrow$ & $8.27 \times 10^{-4}$ & $6.56(0.01)$ & $6.49(0.01)$ \\
\hline Dus11 & 2370138 & $\uparrow$ & $9.30 \times 10^{-4}$ & $7.13(0.01)$ & $7.21(0.02)$ \\
\hline Larp4 & 6400025 & $\downarrow$ & $9.59 \times 10^{-4}$ & $6.47(0.01)$ & $6.41(0.01)$ \\
\hline Alg12 & 3850500 & $\uparrow$ & $9.79 \times 10^{-4}$ & $6.56(0.01)$ & $6.65(0.02)$ \\
\hline ler5l & 4900053 & $\downarrow$ & $9.82 \times 10^{-4}$ & $7.6(0.02)$ & $7.47(0.03)$ \\
\hline $\mathrm{Cc} 126$ & 4560164 & $\downarrow$ & $9.94 \times 10^{-4}$ & $6.49(0.01)$ & $6.41(0.02)$ \\
\hline
\end{tabular}

${ }^{a}$ Arrows denote direction of change in the offspring of older father compared to the offspring of younger fathers. SEM, standard error of the mean. 


\section{Results and discussion}

We found numerous differences in gene expression associated with advanced paternal age. Most notably, probes associated with three transcripts were found to be differentially expressed in the offspring of older fathers compared to the offspring of younger fathers with a false discovery rate (FDR) < 0.1: AA408296 (also known as Diexf $)\left(P=3.23 \times 10^{-6}, \quad \mathrm{FDR}=0.06\right)$ and Lta $(P=$ $\left.3.23 \times 10^{-6}, \mathrm{FDR}=0.06\right)$ had elevated expression, whilst Muc15 $\left(P=7.46 \times 10^{-6}, \mathrm{FDR}=0.06\right)$ had reduced expression (see Figure 1A). Although the absolute differences in gene expression are small and future work is needed to ascertain their functional significance, for each of these differentially expressed transcripts, consistent patterns of altered expression were observed across each of the old-father families (Figure 1B and Additional file 2). The top-ranked differentially expressed transcripts $(P<$ 0.001 ) are listed in Table 1. Strikingly, almost a quarter of these differentially expressed loci have been previously implicated in the aetiology of autism, including Gstm1 (deletion in GSTM1 observed in autism case-parent trios) [16], $C c d c 90 b$ (missense mutation associated with autism in a study of cases and their parents) [17], Cd44 (differential expression in autism discordant monozygotic twins) [18], Accn1 (multiple SNPs associated with autism in a familial study) [19], Shh (increased serum SHH expression in autistic patients compared to nonautistic controls) [20], Dus1l (de novo missense mutation observed in autism families) [21] and Ier5l (increased expression in lymphoblast cells from autism patients in discordant sibling pairs) [22].

Ingenuity pathway analysis (IPA) [23] and the Database for Annotation, Visualization and Integrated Discovery (DAVID) [24,25] were used to identify gene pathways and functions enriched amongst transcripts differentially expressed in the offspring of old fathers. Of note, IPA identified a significant enrichment for functional pathways involved in inflammation and inflammatory disease. Table 2 shows the top-ranked biological functions enriched in probes differentially expressed $(P<0.01)$ in the frontal cortex in the offspring of old fathers. The top-ranked biological network regulates immune cell trafficking and cell-to-cell signalling (Figure 2). Furthermore, the most significantly associated gene ontology term identified by DAVID was immune response $\left(14\right.$ genes, $\left.P=2.87 \times 10^{-4}\right)$ and the second most associated cluster (after cytokine activity) included defence response, response to wounding, inflammatory response and acute inflammatory response. This is interesting given mounting evidence linking the immune system to several neuropsychiatric disorders including autism [26-28]. A recent transcriptomic analysis of post-mortem brains from autistic patients, for example, showed changes in gene networks involved in immune and inflammatory responses in the frontal and temporal cortices [29].
Table 2 Top-ranked biological functions enriched in probes differentially expressed $(P<0.01)$ from IPA

\begin{tabular}{|c|c|}
\hline Biological function & $P$ value \\
\hline Maturation of dendritic cells & $8.99 \times 10^{-5}$ \\
\hline Influx of phagocytes & $1.69 \times 10^{-4}$ \\
\hline Binding of interferon-stimulated response element & $6.43 \times 10^{-4}$ \\
\hline Damage of oligodendrocytes & $7.00 \times 10^{-4}$ \\
\hline Lack of mesenteric lymph node & $7.00 \times 10^{-4}$ \\
\hline Lack of peripheral lymph node & $7.00 \times 10^{-4}$ \\
\hline Stimulation of hyaluronic acid & $7.00 \times 10^{-4}$ \\
\hline Morphology of tooth & $7.56 \times 10^{-4}$ \\
\hline Activation of myeloid cells & $7.78 \times 10^{-4}$ \\
\hline Clustering of lymph node cells & $1.16 \times 10^{-3}$ \\
\hline Osteoclastogenesis of bone cell lines & $1.16 \times 10^{-3}$ \\
\hline Transmigration of Th1 cells & $1.16 \times 10^{-3}$ \\
\hline Influx of neutrophils & $1.21 \times 10^{-3}$ \\
\hline Proliferation of dendritic cells & $1.27 \times 10^{-3}$ \\
\hline Destruction of joint & $1.47 \times 10^{-3}$ \\
\hline Arrest in cell cycle progression of endothelial cells & $1.73 \times 10^{-3}$ \\
\hline Lack of cervical lymph node & $1.73 \times 10^{-3}$ \\
\hline Organogenesis of lymphoid organ & $1.73 \times 10^{-3}$ \\
\hline Response of carcinoma cell lines & $1.73 \times 10^{-3}$ \\
\hline Extravasation of myeloid cells & $1.92 \times 10^{-3}$ \\
\hline Morphogenesis of neurites & $1.97 \times 10^{-3}$ \\
\hline Induction of neuroglia & $2.40 \times 10^{-3}$ \\
\hline Quantity of IL-5 In blood & $2.40 \times 10^{-3}$ \\
\hline Quantity of multinucleated cells & $2.40 \times 10^{-3}$ \\
\hline Response of lung cancer cell lines & $2.40 \times 10^{-3}$ \\
\hline Activation of monocytes & $2.45 \times 10^{-3}$ \\
\hline Acne & $2.48 \times 10^{-3}$ \\
\hline Formation of osteoclasts & $2.60 \times 10^{-3}$ \\
\hline Mobilization of blood cells & $2.63 \times 10^{-3}$ \\
\hline Activation of phagocytes & $2.69 \times 10^{-3}$ \\
\hline Binding of lymphoma cell lines & $2.76 \times 10^{-3}$ \\
\hline Cell viability of blood cells & $2.82 \times 10^{-3}$ \\
\hline Quantity of tooth & $3.17 \times 10^{-3}$ \\
\hline Activation of macrophages & $3.23 \times 10^{-3}$ \\
\hline Proliferation of B lymphocytes & $3.35 \times 10^{-3}$ \\
\hline Response of connective tissue cells & $3.42 \times 10^{-3}$ \\
\hline Cell movement of dendritic cells & $3.88 \times 10^{-3}$ \\
\hline
\end{tabular}

In addition to identifying group-level variation between the offspring of old and young fathers, we also examined family-specific gene expression differences, as many of the genetic (or epigenetic) alterations believed to underlie the paternal age effect in autism are thought likely to be sporadic de novo events occurring in single 


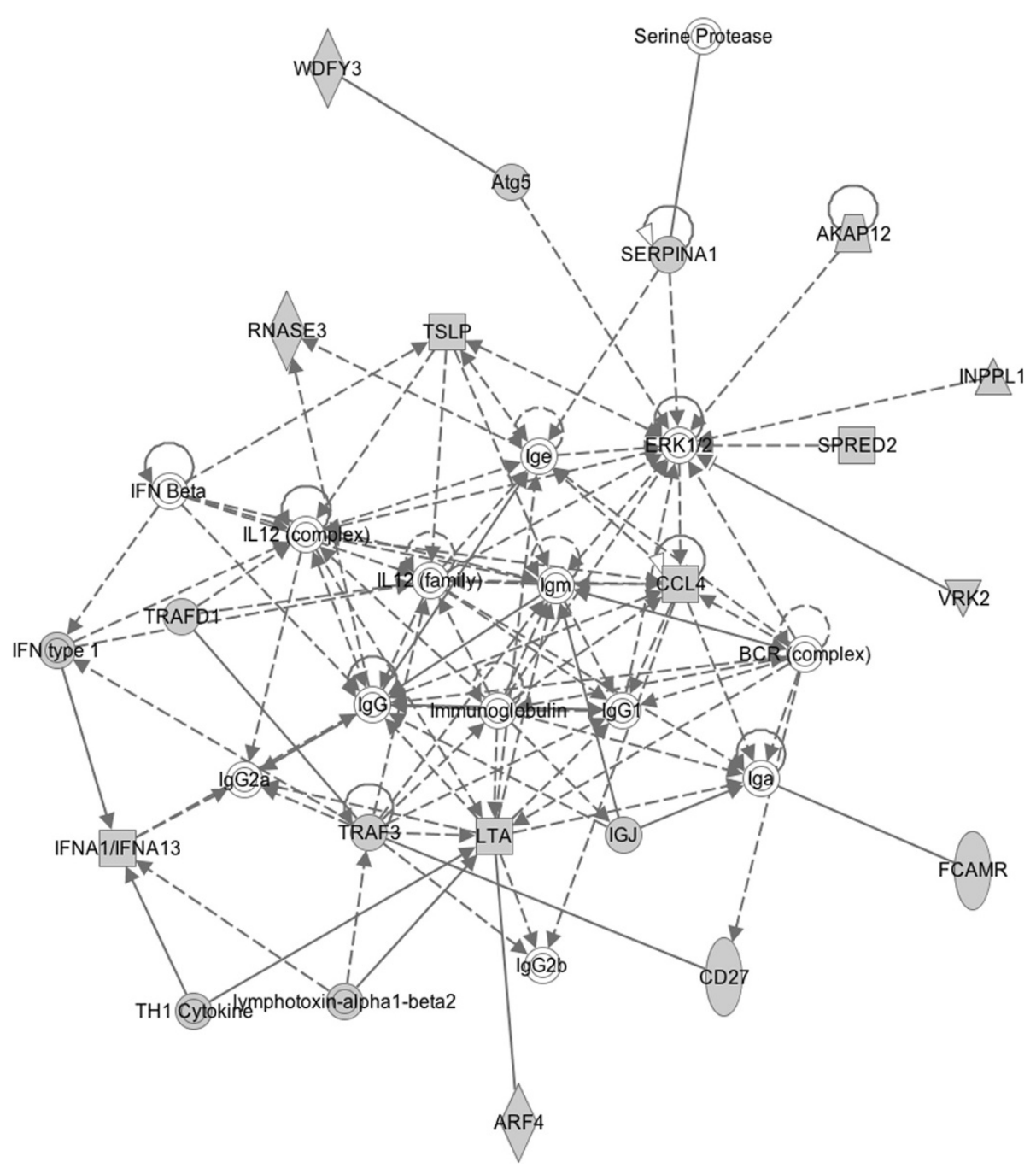

Figure 2 Top-ranked gene network. The network was derived from Ingenuity Pathway Analysis of differentially expressed genes in the offspring of older fathers in a mouse model of advanced paternal age. This network is involved in immune cell trafficking and cell-to-cell signalling. Different shapes relate to different molecule types. The key from Ingenuity can be found at [30].

litters. We compared the average transcript level for all offspring within each family to the average across all offspring of young fathers. We found a 1.8-fold enrichment in the number of family-specific significant gene expression differences in the offspring of older fathers (average 426 differentially expressed genes) compared to the offspring of young fathers (average 234 differentially expressed genes) $(P<$ $0.001)$. Significant probes for each of the six old-father families are listed in Additional file 3. Of note, a number of probes were differentially expressed in the offspring of more than one advanced-age father including probes representing Myst1, Tnfsf11 and Fryl (see Additional file 4).

\section{Conclusions}

We present evidence for transcriptomic differences in the medial prefrontal cortex of offspring of old fathers compared to the offspring of young fathers, including for genes previously implicated in autism, a neuropsychiatric disease epidemiologically associated with advanced paternal age, and an enrichment of loci involved in the inflammatory response. Previous studies of gene expression changes associated with age in the mouse brain have shown enrichment for genes associated with the inflammatory response [8], although this is the first study to examine differences associated with advanced paternal age. Future work will examine whether these expression differences result from de novo genetic (or epigenetic) alterations occurring in the sperm of older fathers.

\section{Availability of supporting data}

The data set supporting the results is available in the Gene Expression Omnibus repository (Currently awaiting upload) or downloaded from our webpage http:// epigenomicslab.com/Paternal Age data.rar. 


\section{Additional files}

\section{Additional file 1: Overview of the samples used in this study. Additional file 2: Significant gene expression differences for individual offspring split by sire for 'young' and 'old' fathers were seen for (A) AA408296, (B) Muc15 and (C) Lta.}

\section{Additional file 3: Top-ranked differentially expressed transcripts} $(P<0.001)$ within each of the six families with an old father. Shown for each transcript is the corresponding rank in the overall old vs young father group comparison.

\section{Additional file 4: Comparison of the top-ranked differentially} expressed transcripts $(P<0.001)$ across each of the six families with an old father. Shown for each transcript is the corresponding rank in the overall old vs young father group comparison. Empty cells indicate a non-significant difference.

\section{Abbreviations}

CNV: copy number variation; DAVID: Database for Annotation, Visualization and Integrated Discovery; FDR: false discovery rate; IL: interleukin; IPA: Ingenuity Pathway Analysis; RIN: RNA integrity number; SNP: single nucleotide polymorphism.

\section{Competing interests}

The authors declare that they have no competing interests.

\section{Authors' contributions}

All authors contributed to the design of the study. RS undertook the lab work. RS and JM drafted the article. RS collected and analysed data, wrote the manuscript, conceived and designed the study, made a critical revision and gave final approval of the manuscript. CF collected data, conceived and designed the study, made a critical revision and gave final approval of the manuscript. RK collected data, made a critical revision and gave final approval of the manuscript. LS analysed the data, made a critical revision and gave final approval of the manuscript. JB and AR conceived and designed the study, provided financial support, made a critical revision and gave final approval of the manuscript. JM wrote the manuscript, conceived and designed the study, made a critical revision and gave final approval of the manuscript. All authors read and approved the final manuscript.

\section{Acknowledgements}

This study was supported by the Beatrice and Samuel A Seaver Foundation, by a British Medical Association Margaret Temple Award, and the National Institute of Health Research Biomedical Research Centre for Mental Health at the South London and Maudsley National Health Service Foundation Trust and the Institute of Psychiatry, King's College London, Pilot Award to Drs Jonathan Mill and Abraham (Avi) Reichenberg.

\section{Author details}

${ }^{1}$ Institute of Psychiatry, King's College London, De Crespigny Park, Denmark Hill, London SE5 8AF, UK. ${ }^{2}$ Mount Sinai School of Medicine, Madison Avenue, New York, NY 10029, USA. 'University of Exeter Medical School, St Luke's Campus, Magdalen Rd, Exeter EX1 2LU, UK.

Received: 10 October 2013 Accepted: 10 March 2014

Published: 23 March 2014

\section{References}

1. Lundstrom S, Haworth CM, Carlstrom E, Gillberg C, Mill J, Rastam M, Hultman CM, Ronald A, Anckarsater H, Plomin R, Lichtenstein P, Reichenberg A: Trajectories leading to autism spectrum disorders are affected by paternal age: findings from two nationally representative twin studies. J Child Psychol Psychiatry 2010, 51(7):850-856.

2. Kong A, Frigge ML, Masson G, Besenbacher S, Sulem P, Magnusson G, Gudjonsson SA, Sigurdsson A, Jonasdottir A, Wong WS, Sigurdsson G, Walters GB, Steinberg S, Helgason H, Thorleifsson G, Gudbjartsson DF, Helgason A, Magnusson OT, Thorsteinsdottir U, Stefansson K: Rate of de novo mutations and the importance of father's age to disease risk. Nature 2012, 488(7412):471-475

3. Adkins RM, Thomas F, Tylavsky FA, Krushkal J: Parental ages and levels of DNA methylation in the newborn are correlated. BMC Med Genet 2011, 12:47.
4. Flatscher-Bader T, Foldi CJ, Chong S, Whitelaw E, Moser RJ, Burne TH, Eyles DW, McGrath JJ: Increased de novo copy number variants in the offspring of older males. Trans/ Psychiatr 2011, 1:e34.

5. Smith RG, Reichenberg A, Kember RL, Buxbaum JD, Schalkwyk L, Fernandes C, Mill J: Advanced paternal age is associated with altered DNA methylation at brain-expressed imprinted loci in inbred mice: implications for neuropsychiatric disease. Mol Psychiatry 2013, 18(6):635-636.

6. Colangelo V, Schurr J, Ball MJ, Pelaez RP, Bazan NG, Lukiw WJ: Gene expression profiling of 12633 genes in Alzheimer hippocampal CA1: transcription and neurotrophic factor down-regulation and upregulation of apoptotic and pro-inflammatory signaling. J Neurosci Res 2002, 70(3):462-473.

7. Valdes AM, Glass D, Spector TD: Omics technologies and the study of human ageing. Nat Rev Genet 2013, 14(9):601-607.

8. Lee CK, Weindruch R, Prolla TA: Gene-expression profile of the ageing brain in mice. Nat Genet 2000, 25(3):294-297.

9. Paul C, Nagano M, Robaire B: Aging results in differential regulation of DNA repair pathways in pachytene spermatocytes in the brown Norway rat. Biol Reprod 2011, 85(6):1269-1278.

10. Kokkinaki M, Lee TL, He Z, Jiang J, Golestaneh N, Hofmann MC, Chan WY, Dym M: Age affects gene expression in mouse spermatogonial stem/ progenitor cells. Reproduction 2010, 139(6):1011-1020.

11. Alter MD, Kharkar R, Ramsey KE, Craig DW, Melmed RD, Grebe TA, Bay RC, Ober-Reynolds S, Kirwan J, Jones JJ, Turner JB, Hen R, Stephan DA: Autism and increased paternal age related changes in global levels of gene expression regulation. PLoS One 2011, 6(2):e16715.

12. Paxinos G: The Mouse Brain in Stereotaxic Coordinates. London: Academic press; 2004.

13. Spijker S: Dissection of rodent brain regions. In Neuroproteomics. New York, NY, USA: Humana Press Inc, Springer; 2011:13-26.

14. Johnson WE, Li C, Rabinovic A: Adjusting batch effects in microarray expression data using empirical Bayes methods. Biostatistics 2007, 8(1):118-127.

15. Du P, Kibbe WA, Lin SM: Lumi: a pipeline for processing Illumina microarray. Bioinformatics 2008, 24(13):1547-1548.

16. Buyske $S$, Williams TA, Mars AE, Stenroos ES, Ming SX, Wang R, Sreenath M, Factura MF, Reddy C, Lambert GH, Johnson WG: Analysis of case-parent trios at a locus with a deletion allele: association of GSTM1 with autism. BMC Genet 2006, 7:8.

17. Neale BM, Kou Y, Liu L, Ma'ayan A, Samocha KE, Sabo A, Lin CF, Stevens C, Wang LS, Makarov V, Polak P, Yoon S, Maguire J, Crawford EL, Campbell NG, Geller ET, Valladares O, Schafer C, Liu H, Zhao T, Cai G, Lihm J, Dannenfelser R, Jabado O, Peralta Z, Nagaswamy U, Muzny D, Reid JG, Newsham I, Wu YMJ, et al: Patterns and rates of exonic de novo mutations in autism spectrum disorders. Nature 2012, 485(7397):242-245.

18. Hu WW, Frank BC, Heine S, Lee NH, Quackenbush J: Gene expression profiling of lymphoblastoid cell lines from monozygotic twins discordant in severity of autism reveals differential regulation of neurologically relevant genes. BMC Genomics 2006, 7:118.

19. Stone JL, Merriman B, Cantor RM, Geschwind DH, Nelson SF: High density SNP association study of a major autism linkage region on chromosome 17. Hum Mol Genet 2007, 16(6):704-715

20. Al-Ayadhi LY: Relationship between Sonic hedgehog protein, brain-derived neurotrophic factor and oxidative stress in autism spectrum disorders. Neurochem Res 2012, 37(2):394-400.

21. O'Roak BJ, Vives L, Girirajan S, Karakoc E, Krumm N, Coe BP, Levy R, Ko A, Lee C, Smith JD, Turner EH, Stanaway IB, Vernot B, Malig M, Baker C, Reilly B, Akey JM, Borenstein E, Rieder MJ, Nickerson DA, Bernier R, Shendure J, Eichler EE: Sporadic autism exomes reveal a highly interconnected protein network of de novo mutations. Nature 2012, 485(7397):246-250.

22. Hu WW, Nguyen A, Kim KS, Steinberg ME, Sarachana T, Scully MA, Soldin SJ, LuU T, Lee NH: Gene expression profiling of lymphoblasts from autistic and nonaffected sib pairs: altered pathways in neuronal development and steroid biosynthesis. PLoS One 2009, 4(6):e5775.

23. Ingenuity Pathway Analysis. [http://www.ingenuity.com/products/ipa]

24. Huang DW, Sherman BT, Lempicki RA: Systematic and integrative analysis of large gene lists using DAVID bioinformatics resources. Nat Protoc 2009, 4(1):44-57.

25. Huang DW, Sherman BT, Lempicki RA: Bioinformatics enrichment tools: paths toward the comprehensive functional analysis of large gene lists. Nucleic Acids Res 2009, 37(1):1-13.

26. Onore $C$, Careaga $M$, Ashwood $P$ : The role of immune dysfunction in the pathophysiology of autism. Brain Behav Immun 2012, 26(3):383-392. 
27. Noriega DB, Savelkoul HF: Immune dysregulation in autism spectrum disorder. Eur J Pediatr 2013, 173(1):33-43.

28. Michel M, Schmidt MJ, Mirnics K: Immune system gene dysregulation in autism and schizophrenia. Dev Neurobiol 2012, 72(10):1277-1287.

29. Voineagu I, Wang X, Johnston P, Lowe JK, Tian Y, Horvath S, Mill J, Cantor RM, Blencowe BJ, Geschwind DH: Transcriptomic analysis of autistic brain reveals convergent molecular pathology. Nature 2011, 474(7351):380-384.

30. Ingenuity Pathway Analysis legend. [http://www.biolreprod.org/content/ suppl/2011/02/23/biolreprod.110.090019.DC1/90019SupLegend.pdf]

doi:10.1186/2040-2392-5-24

Cite this article as: Smith et al:: Transcriptomic changes in the frontal

cortex associated with paternal age. Molecular Autism 2014 5:24.

\section{Submit your next manuscript to BioMed Central and take full advantage of:}

- Convenient online submission

- Thorough peer review

- No space constraints or color figure charges

- Immediate publication on acceptance

- Inclusion in PubMed, CAS, Scopus and Google Scholar

- Research which is freely available for redistribution 